\title{
SOCIEDADE DE CONSUMIDORES E O DESINTERESSE PELA ESFERA PÚBLICA: ESCRAVIZAÇÃ̃O INVISÍVEL E A POLÍTICA INSTRUMENTAL EM HANNAH ARENDT
}

\author{
Kelly Janaína Souza da Silva ${ }^{1}$ \\ Universidade Federal de Santa Catarina (UFSC) \\ https://orcid.org/0000-0002-8836-9376 \\ E-mail: kelly_phoenix@hotmail.com
}

\section{RESUMO:}

Erigir o aumento da riqueza e da abundância como um objetivo primordial para a vita activa já se desenhava como premissa axiomática da economia política clássica, além do sonho idealizado dos pobres e despossuídos. Havia, no entanto, certa esperança utópica de que, ao viver em uma sociedade com maior abastança, as pessoas cidadãs buscariam mais plenamente o desenvolvimento de apropriada abstenção consciente do trabalho e do consumo em seu tempo livre, ou seja: que isento da dor e do esforço de trabalhar e consumir, o animal laborans tornar-se-ia produtivo para si próprio, nutrindo-se de atividades "superiores". No entanto, de quanto mais horas vagas dispõe o laborans, maiores são seus apetites de consumo e, sobretudo, uma sociedade abundante expõe devidamente a falácia do raciocínio anterior, uma vez que tudo pode ser reificado e comercializado. Esse artigo pretende analisar o fenômeno da sociedade de consumo contemporânea como engrenagem do ciclo vital, descrevendo de que modo, presas em seus próprios processos de trabalho e consumo, as pessoas cidadãs desfrutam apenas de uma política instrumental. Essa alienação promove a vitória do animal laborans sobre o zoon politikon.

PALAVRAS-CHAVE: Sociedade de Consumidores; Política Instrumental; Ciclo Vital.

\section{THE CONSUMPTION SOCIETY AND THE APATHY FOR THE PUBLIC REALM: THE INVISIBLE SLAVERY AND THE INSTRUMENTAL POLICY BY HANNAH ARENDT}

\begin{abstract}
:
Erecting the increase of wealth and abundance as a primary objective for the active vita was already devised as the axiomatic premise of classical political economy, as well as the idealized dream of the poor and dispossessed people. There was, however, a certain utopian hope that by living in a society with greater wealth the citizens would more fully seek the development of appropriate conscious abstention from labor and consumption in their free time, ie: free from pain and of the effort to work and to consume, the animal laborans would become productive for itself, nourishing itself with "superior" activities. However, how much free time the laborans has, the greater are their appetites for consumption, and more than that, an abundant society properly exposes the fallacy of that previous reasoning, since everything can be reified and marketed. This article intends to analyze the phenomenon of contemporary consumer society as a cog in the life cycle, describing why the citizens have just an instrumental policy in their own processes of labor and consumption. This alienation promotes the victory of animal laborans over zoon politikon.
\end{abstract}

KEYWORDS: Consumption Society; Instrumental Policy; Life Cycle.

\footnotetext{
${ }^{1}$ Doutoranda em Filosofia na Universidade Federal de Santa Catarina (UFSC), Florianópolis - SC, Brasil, com período sanduíche em Freie Universität Berlin (FU Berlin), Berlim, Alemanha. Bolsista do(a): Coordenação de Aperfeiçoamento de Pessoal de Nível Superior, CAPES, Brasil. Bolsa CAPES/PROEX.
}

SILVA, Kelly Janaína Souza da. Sociedade de Consumidores e o desinteresse pela esfera pública: escravização invisível e a política instrumental em Hannah Arendt. Griot : Revista de Filosofia, Amargosa - BA, v.19, n.2, p.218-229, junho, 2019. 
Passeio meu olhar sobre essa multidão inumerável, composta de seres parecidos, onde nada se eleva nem se abaixa (TOCQUEVILLE, 1969, p. $362)$.

Você tem milhares de chances de ganhar prêmios de até $\mathbf{R} \$ 10$ mil. Achou, ganhou. We can do it. O que você vai pedir hoje? Três hambúrgueres, alface, queijo, molho especial, cebola, picles e um pão com gergelim. Contém aromatizante sintético idêntico ao natural. $145 \mathrm{~g}$. Perfuma o hálito, limpa, embeleza e protege os dentes. Não contém glúten. Analgésico e antiinflamatório. Alívio prolongado para muitos tipos de dor. Diet: perca peso com saúde. Uso oral adulto e pediátrico. Ultra proteção. Normal. Sem abas. 123 calorias de energia positiva. Abra a felicidade. $O$ melhor presente para o melhor pai. Perfumaria masculina. Cílios até $43 \%$ mais longos. We want you.

\section{A modernidade se inaugura com um código de barras}

A primeira vez que Arendt mencionou a expressão "sociedade de consumidores", em $A$ condição humana, o fez para reforçar o argumento de que o trabalho $^{2}$ (labor) e o consumo - como dois estágios do mesmo processo, - eram impostos ao ser humano pelas próprias necessidades vitais e que, da mesma forma, impeliam as vidas humanas a (sobre)viver em uma sociedade de trabalhadores (Laboring society). Sua observação de que tal advento estava diretamente relacionado à emancipação do trabalho, e não da pessoa trabalhadora, e de que todas as atividades de trabalho tinham como denominador comum a produção de coisas necessárias à manutenção da vida, e de produzi-las em abundância, deixava claro o veredicto, então, da condição de reduzir praticamente todas as profissões ao provimento do próprio sustento da pessoa que trabalha. $O$ que diria a politóloga ${ }^{3}$ hoje, diante do cenário que se nos apresenta, o qual uma sociedade de indivíduos condenou a cena política aos trâmites econômicos e ao "governo"; e ao consumo das massas, vertidas em multidões solitárias ${ }^{4}$, que se socorrem no ato de consumir da demência de não ver possibilidade em escapar ao ciclo vital? Uma política restrita à elaboração e administração de estratégias para o desenvolvimento livre do progresso; e um consumo que incorre desde a sobrevivência básica até a ditadura de estilos de vida, devorando bens não duráveis bem como relações humanas, e que dissipa as horas vagas das massas com o divertimento fabricado para elas.

A escolha em trabalhar Hannah Arendt não parte de uma constatação gratuita: entre tantas possibilidades de diagnosticar um futuro ante a Revolução Industrial e o pós guerra, a pensadora foi certeira em sua previsão de que, diante da condição humana contingente marcada pela natalidade, a pluralidade, a ação e o

\footnotetext{
2 No original, em inglês, Arendt utiliza os termos labor, work e action. Em alemão, Arendt usa os verbos substantivados: Arbeiten, Herstellen e Handeln (cf. Arendt, 1960). A tradução em português usava os substantivos: labor, trabalho e ação (cf. Arendt, 2001) até que Correia sugeriu outra tradução, substituindo labor e trabalho, respectivamente, por trabalho e obra (cf. nota sobre a traduçáo em Arendt, 2005, p. 196). Nesse trabalho, utilizo a tradução conforme Correia.

3 Arendt pode ser considerada uma teórica política, mas não pensava o Estado.

${ }^{4}$ Referência à obra "A multidão solitária" (The lonely crowd), de David Riesman (1950), sobre o desamparo moderno como fenômeno de massa.
}

SILVA, Kelly Janaína Souza da. Sociedade de Consumidores e o desinteresse pela esfera pública: escravização invisível e a política instrumental em Hannah Arendt. Griot : Revista de Filosofia, Amargosa - BA, v.19, n.2, p.218-229, junho, 2019. 
pensamento, as questões humanas mais importantes não poderiam ser deixadas a cargo de cientistas profissionais e políticos profissionais. As manifestações mais elementares da condição humana são atividades ao alcance de todo ser humano, e as preocupações de Arendt já emanavam a importância do resgate da pluralidade e dignidade humanas por meio da ação política - algo que exige, minimamente, uma ruptura com o ideal da sociedade de consumidores que, agora, mais do que à época que a autora se debruçou, se evidencia em uma realidade indubitável.

Para a pensadora alemã, o fundamento filosófico-político que explica a constituição da pessoa humana contemporânea se resume a três atividades - e estas compõem a vita activa: trabalho (labor), obra (work) e ação (action). O trabalho trata da atividade responsável pela manutenção da vida, indistinguindo-se do labor animal, uma vez que tanto um como outro, humano e animal, precisam manter seu organismo biológico vivo para o suprimento de suas necessidades básicas. Em Arendt, o trabalho tem correspondência com o processo biológico humano, sendo sua condição humana a própria vida. Quanto à obra, versa sobre a artificialidade com a qual a pessoa humana produz, a partir de suas próprias mãos, um mundo próprio que, ainda que sintético, é durável. Corresponde à artificialidade da existência humana, produzindo um "mundo artificial" de coisas, que difere de qualquer ambiente natural, e cuja condição é a mundanidade. É importante observar que tanto nas línguas europeias antigas quanto nas modernas, existem duas palavras de etimologia diferente para designar labor e work, elementos os quais, contemporaneamente, muitas vezes, são tidos como sinônimos e significantes da mesma atividade. Hannah Arendt demarca bem a diferença entre elas, enfatizando que para a primeira o fator humano se torna o animal laborans, e para a segunda, torna-se ele o homo faber 5 .

A ação é a condição humana para a vida em pluralidade, a vida política. Sem a necessidade do artifício ou da matéria, a ação exprime a própria relação e expressão de indivíduo singular para indivíduo singular em uma comunidade plural. É esse elemento, dos três, o que guarda a mais íntima relação com a política, uma vez que a condição para ambos é a pluralidade. E o espaço que visa à ação é o espaço público, em que os atos e as palavras (discursos) estarão presentes para revelá-la; sendo esse espaço público tanto o espaço de aparição ("das aparências", em que é preciso ser visto e ouvido), quanto o espaço compartilhado, que rege um mundo comum, com interesses comuns e que visa a um bem comum (sensus communis).

\footnotetext{
${ }^{5}$ Em A Condição Humana, Arendt diz que não sabe exatamente quando a expressão homo faber surgiu pela primeira vez. O homo faber tem a fabricação como trabalho e, pode-se dizer que ele é o criador do artifício humano, dependendo das mãos como instrumento. No mundo do homo faber, tudo deve ter seu fim ou servir de finalidade a outra coisa. Para distinguir o homo faber do animal laborans, pode-se mencionar que enquanto o primeiro se preocupava em fabricar coisas, o segundo se utiliza das ferramentas elaboradas pelo homo faber para amainar suas atividades. O animal laborans vive dos desejos, não da necessidade, e tem no consumo a alegria da satisfação de seu ciclo vital. Traduz-se, basicamente, pela produção de seus meios de subsistência. É importante ressaltar, porém, que todas e todos somos/ estamos em ambos os papeis, simultaneamente. E talvez também se deva destacar que nosso consumo abrange tanto os bens de consumo advindos diretamente do trabalho (como um pão, por exemplo), quanto objetos de uso produzidos por meio da obra do homo faber (uma mesa, por exemplo). Aliás, tratar todos os objetos de uso como bens de consumo, para que sejam consumidos rapidamente, é uma das máximas da sociedade de abundância, para que se busque superar a limitação natural da fertilidade humana (CH, p. 154).
}

SILVA, Kelly Janaína Souza da. Sociedade de Consumidores e o desinteresse pela esfera pública: escravização invisível e a política instrumental em Hannah Arendt. Griot : Revista de Filosofia, Amargosa - BA, v.19, n.2, p.218-229, junho, 2019. 
Nesse sentido, tem-se que Hannah Arendt concebe o senso comum a partir da acepção kantiana do termo. Immanuel Kant distingue a expressão "senso comum", utilizada coloquialmente, como um entendimento salutar que a pessoa humana porta (por isso "comum"), de sensus communis, conceito que compreende uma faculdade de ajuizamento que, a priori, toma em consideração o modo de representação de qualquer outra pessoa, como que para fundamentar um juízo à razão humana. Ou seja, o senso comum aqui abordado trata da necessidade de um espaço do mundo comum compartilhado para a efetivação da existência de cada ator político, uma vez que não é, senão, mediante acordos institucionalizados pela lei que se dá o estabelecimento do espaço político por excelência.

O que se vive hoje é um preceito de capitalismo globalizado, que semelhante à técnica heideggeriana, é o que organiza relações (inclusive humanas) e o sistema temporal $\left(24 / 7^{6}\right.$, por exemplo, ou mesmo, fábricas e shoppings sem janelas, para que se perca a noção do tempo), e que segue as máximas de Hobbes, Locke e Marx, tomando a política como um meio para um fim, quando ela deveria ser um fim em si mesma. A partir do enfraquecimento da dimensão humana da ação, - o que, inicialmente, levou ao suplante do homo faber, com a fabricação de bens duráveis e produção de mundanidade como principal atividade; - a política, nesse ínterim, ficou relegada a um papel técnico, sujeita à habilidade fabril, com o desempenho representativo de um governante tomando o lugar do dado plural. A isso, seguiu-se que os mais diversos âmbitos da vida passaram a convergir para relações de consumo, com o trabalho assumindo a função de conservação das necessidades. Então, a utilidade do homo faber rendeu-se à necessidade do animal laborans, e consumo e trabalho passaram ao protagonismo no que tange à manutenção da vida cotidiana, lançando a durabilidade do mundo a corromper-se e as coisas a serem fabricadas para consumo imediato, o que induziu, ainda, à perda de valor e de estabilidade, e à impossibilidade do sustento de um "mundo comum". Sob tal privilégio do econômico em detrimento do político, instala-se uma situação de escravização invisível, que impede que se tenha a liberdade necessária para a constituição de um mundo compartilhado.

Arendt já percebia que tal ideal não era algo novo: erigir o aumento da riqueza e da abundância como um objetivo primordial para a vita activa já se desenhava como premissa axiomática da economia política clássica, além do sonho idealizado dos pobres e despossuídos. Havia, no entanto, certa esperança utópica de que, ao viver em uma sociedade com maior abastança, as pessoas cidadãs buscariam mais plenamente o desenvolvimento de apropriada abstenção consciente do trabalho e do consumo em seu tempo livre, ou seja: que isento da dor e do esforço de trabalhar e consumir, o animal laborans tornar-se-ia produtivo para si próprio, nutrindo-se de atividades "superiores". No entanto, de quanto mais horas vagas dispõe o laborans, maiores são seus apetites de consumo e, sobretudo, uma sociedade abundante expõe devidamente a falácia do raciocínio anterior, uma vez que tudo pode ser reificado e comercializado. Alguns exemplos contemporâneos: vida natural, ou "vida verde" (hipster); ideias sobre o que seja empoderamento feminino; moda (por exemplo,

${ }^{6}$ Sobre a elaboração temporal a partir do capitalismo, ler: CRARY, Jonathan. 24/7 - Capitalismo tardio e os fins do sono, que trata acerca de estudos que já apontam a uma futura disponibilidade humana em consumir, trabalhar e responder durante 24 horas por dia, 7 dias por semana, e o quanto isso seria nocivo à humanidade.

SILVA, Kelly Janaína Souza da. Sociedade de Consumidores e o desinteresse pela esfera pública: escravização invisível e a política instrumental em Hannah Arendt. Griot : Revista de Filosofia, Amargosa - BA, v.19, n.2, p.218-229, junho, 2019. 
tendências retrôs que visam a fugir do mainstream); aplicativos para procurar relacionamentos amorosos; pornografia e prostituição (em que o corpo é apenas um produto); a própria arte; ou seja, absolutamente tudo pode ser caracterizado como mercadoria, - o sexo, a água, a fé, o conhecimento, a saúde, a morte; - e medido pelos critérios do consumo, substituição constante, ausência de durabilidade e conveniência para quem consome. Daí também uma série de patologias neoliberais, que buscam responsabilizar o indivíduo por todas as esferas de sua vida (ex.: o seguro do carro; o seguro de saúde; o seguro de vida), e que acarretam na morte do sujeito, deixando dele apenas o indivíduo - assim, não há sociedade, apenas mercado, o que mina a possibilidade política.

Tem-se, ainda, a industrialização do entretenimento; a laborização do tempo livre e a fabricação geral de qualquer outra atividade, pois tudo passou a ser percebido em função da geração da abundância. E a abundância não implica, necessariamente, na possibilidade do exercício da cidadania; ao contrário: as sociedades consumistas mostram-se muito sofisticadas em manter cidadãs e cidadãos apenas como meros consumidores e a economia como uma condição de possibilidade para o político. Oikos é, então, a condição e o oposto da esfera pública.

Tendo em vista que o fator humano ocupa-se apenas de seu ciclo vital, de sobreviver, trabalhar e consumir, há uma tendência natural à expansão da solidão, além da alienação, nas sociedades abundantes. Sem a intervenção de um estatuto de Bem Comum, o sensus communis é transformado em alimentação, vestuário, teto e condições reprodutivas, empobrecendo a concepção de propriedade sob a égide social. $O$ problema que Arendt aponta, no entanto, não trata de demonizar a questão social, mas de perceber que sua absolutização enquanto objetivo político acarreta na própria eliminação da política, pois esta está muito acima da usual compreensão burocrática que destaca a organização da vida coletiva e a garantia de aplicação da lei. Para Arendt, somente a constituição de uma nova forma de governo, em que a cidadania pudesse ser efetiva, superaria a opressão realizada pelos moldes convencionais ${ }^{7}$. Todavia, a liberação do processo imposto pelo ciclo vital só é possível com a atividade de pensar, mas esta se trata de ferramenta individual, cujos efeitos na coletividade podem ser pouco sentidos, ou demorarem a surtir resultados, uma vez que esta atividade não se manifesta no mundo, necessariamente, "nem precisa ser ouvida, vista, usada ou consumida para ser real" (ARENDT, 2010, p. 117).

Nesse ínterim, é preciso também traçar as semelhanças e os paralelos entre o que constitui uma sociedade de consumidores e o que constitui uma sociedade de massa, e em que uma e outra contribuem ao cenário político contemporâneo e à constatação de que o sensus communis, atualmente, está depreciado a tal ponto que já não é possível exercer o julgamento. Segundo a pensadora política, a sociedade de massas surge a partir da absorção dos diversos grupos sociais em uma sociedade

\footnotetext{
${ }^{7}$ Em Arendt, tal recriação do espaço público não se trata de uma necessidade comunitarista, ou por via moral. A questão é que a sociedade em grande escala está fraturada e a solução não é se juntar em pequenas comunidades alternativas, mas uma nova constituição política, cujo conteúdo não se sabe ao certo (mas, pode-se arriscar, parece caminhar a uma nova revolução americana). Para tal, existem duas saídas: a grega e a americanófila (esta, citada em On Revolution e em Crises of the Republic). A revolução, para Arendt, é considerada o reviver da liberdade da esfera pública.
}

SILVA, Kelly Janaína Souza da. Sociedade de Consumidores e o desinteresse pela esfera pública: escravização invisível e a política instrumental em Hannah Arendt. Griot : Revista de Filosofia, Amargosa - BA, v.19, n.2, p.218-229, junho, 2019. 
única, possibilitada pela ascensão da esfera social sobre a esfera política ${ }^{8}$. Isto é, o zoon politikon é confundido com o animal socialis, e sua característica essencial é a indiferença pelos assuntos de cunho comum. Ainda segundo a autora, o princípio estruturante da formação das massas modernas se constitui a partir da desarticulação da sociedade de classes. Com o esfacelamento dos Estados-nações, a estratificação da sociedade desaparece, e sem ela não é possível reconhecer um indivíduo pela camada a qual "pertence". Não se tem mais, então, a luta em prol dos interesses de uma classe específica, e a pirâmide social cede por sua base, dando lugar a uma sociedade de consumo com profundo desinteresse pela esfera pública. Ao substituir a preocupação pelos interesses de uma comunidade ou classe pela preocupação exclusiva com a sobrevivência individual, naturaliza-se a apatia e a hostilidade pelos assuntos de cunho coletivo. Nesse sentido, tem-se um ser humano reduzido à função de suporte ao ciclo vital, tornado substituível e supérfluo, além de facilmente controlado (controlável). A pessoa humana é, logo, intercambiável, pois serve apenas como meio para o progresso social, e assim perde a liberdade de agir no mundo. Isso, para Arendt, parece dificultar a premissa de uma liberdade que se revele a partir da ação e no interior da política. Uma vez que não há o exercício do pensar e, consequentemente do juízo, o cidadão - aqui ocupado no papel de consumidor, - encontra-se impossibilitado de promover a vida ativa de seu espírito junto à comunidade política, pois quando a atenção dos indivíduos está voltada apenas à vida privada, sem dar importância ou ignorando a vida pública, o poder que poderia ser político e democrático é, então, outorgado às institucionalizações e ao conseguinte abandono do bem comum.

Embora a expressão "sociedade de massa" tenha sido cunhada com a especificidade de discriminar aquela sociedade que, com um número considerável de pessoas apáticas politicamente, alimentou os regimes totalitários do século XX, importa destacar que a indiferença pelos assuntos comuns e a identificação com reações previsíveis seguem pouco influenciadas na atual sociedade de consumo, e que isso dá lastro a outros fenômenos de imanência política, ainda que, aparentemente, mais sutis. A massa continua presente enquanto há um grande número de pessoas indiferentes, o que não permite um engajamento comum. $O$ ser político de hoje não somente aceita, como por vezes parece anuir em ter seu papel reduzido ao de mero consumidor - um tanto por preguiça, outro tanto por ignorância, outro tanto, ainda, pelo sentimento de impotência; mas os cidadãos e cidadãs parecem conformar-se em apenas fazer parte da engrenagem e não protagonizar o seu papel político. Além disso, as reflexões arendtianas parecem apontar que muitas nações ditas democráticas estão repletas de elementos totalitários, explicado pelo fato de que muitas democracias liberais transformaram a atividade política apenas em administração burocrática das necessidades sociais (DUARTE, 2002, p. 59),

\footnotetext{
${ }^{8}$ Nesse trabalho, as expressões "pessoa da massa" e "sociedade de massa" atenderão, então, ao conceito dos cidadãos e cidadãs que, integrantes de uma comunidade política (Estado ou Nação), não desempenham sua efetivação junto a ela pela ação, ou seja, homens e mulheres que acatam ao processo de sobrevivência regulado pelo trabalho e o consumo, porém, sem participação política plena (isto é, concorrendo à constituição da comunidade política) ante o pensamento e o juízo; apenas aderindo aos comportamentos e regras pré-definidos pela "sociedade de massa".
}

SILVA, Kelly Janaína Souza da. Sociedade de Consumidores e o desinteresse pela esfera pública: escravização invisível e a política instrumental em Hannah Arendt. Griot : Revista de Filosofia, Amargosa - BA, v.19, n.2, p.218-229, junho, 2019. 
subsumindo a verdadeira função do político propriamente dito, e dificultando o espaço para a ocorrência da ação dos cidadãos e cidadãs "comuns".

É também observando por esse ângulo que, apresentando-se a sociedade de consumidores como uma organização que opera a partir de atividades repetitivas baseadas em produção e consumo, pode-se dizer que as pessoas que integram essa comunidade tornam-se, de certo modo, escravas, por sua incapacidade adquirida de pensar e questionar o que quer que seja, e a ausência de percepção dessa circunstância. Na sociedade dita "de escravos", a própria vida em escravidão testemunhava diariamente a maldição da necessidade, enquanto que contemporaneamente, essa condição já não é inteiramente manifesta, fazendo com que o sujeito de necessidades ignore que não é livre (ARENDT, 2001, p. 133). Naturalizou-se a dominação estrutural, a qual, nos obriga a trabalhar para comer; ter um trabalho assalariado, "se formar" $\mathrm{e}$ "subir na vida", e a liberdade do indivíduo é conjugada em uma possível abstração ideológica, que o isenta da responsabilidade com o comunitário e, mesmo, da ciência de sua condição.

O modelo vivenciado, então, propicia que tal constituição social componha-se por pessoas cada vez mais individualistas e individualizadas, isto é, massas atomizadas. Enquanto indivíduo atômico, suprime-se-lhe os interesses de um mundo comum (perda do sensus communis) em detrimento de seu condicionamento para interesses funcionais - cada pessoa humana funciona como uma pequena parte no todo da engrenagem social e constitucional, geralmente guiada por uma mentalidade utilitarista que se faz presente desde o discurso pedagógico-educacional 9 (impossibilitando o desenvolvimento do pensar, uma vez que a reflexão não produz resultados objetivos), até a total ausência de pensamento autônomo ${ }^{10}$ - e que tem na figura de Adolf Eichmann o retrato personificado: um ser humano carente de consciência moral e capacidade política, prisioneiro das necessidades e sem motivações extemporâneas. Isto é, um funcionário banal que se preocupa apenas com as burocracias de sua profissão, e as cumpre de forma totalmente mecânica, sem ajuizar acerca das possíveis consequências de suas ações.

Responsável pelo transporte de prisioneiros aos campos de concentração do Terceiro Reich, Adolf Karl Eichmann foi levado a julgamento em Jerusalém no ano de 1961 - julgamento, o qual, Hannah Arendt esteve presente; - e suas respostas durante o interrogatório demonstraram que acreditava ter agido puramente por um dever profissional, estando assim, isento de qualquer responsabilidade e culpa. Não havia nele qualquer sinal de motivações más que o levassem à ação, ou mesmo, convicções ideológicas firmes que justificassem seus atos; "[...] não era estupidez, mas irreflexão" (ARENDT, 2002, p. 6) ${ }^{11}$. Embora Eichmann tenha se valido do

\footnotetext{
${ }^{9} \mathrm{Em}$ Entre o passado e o futuro ("Crise da Educação"), Arendt defende que a escola pode ser considerada como processo de transição da esfera privada para a esfera pública, e sendo assim, de certa forma prepara o educando para a vida política.

10 Aqui, trata-se do conceito de autonomia em Immanuel Kant. Compreende um estado de "maioridade", em que a pessoa humana autônoma é responsável por seus atos e passa da heteronomia a um estado em que é sua autolegisladora. Para que chegue a esse estado autônomo, é preciso conquistar o esclarecimento (Aufklärung), que vem a ser o processo de emancipação intelectual que supera a ignorância e a preguiça de pensar por si próprio, além do desenvolvimento da crítica àquilo que é inculcado intelectualmente pelos demais (sejam outras pessoas humanas, instituições ou governos).

11 Grifo da autora.
}

SILVA, Kelly Janaína Souza da. Sociedade de Consumidores e o desinteresse pela esfera pública: escravização invisível e a política instrumental em Hannah Arendt. Griot : Revista de Filosofia, Amargosa - BA, v.19, n.2, p.218-229, junho, 2019. 
imperativo categórico de Kant para sua defesa, a filosofia moral kantiana está diretamente associada à faculdade do juízo humano, o que elimina a obediência cega. Para Arendt, o agente manifestava em sua omissão a mais pura ausência de pensamento, uma vez que não podia refletir acerca dos atos que praticara. Com obediência cega ao sistema do qual fazia parte, Eichmann não questionou o sentido de suas ações e, sem reflexão ou espontaneidade se acreditou apenas na condição de um instrumento, não se utilizando de um juízo reflexivo. Esclarecendo que a espontaneidade é o que caracteriza a individualidade de cada um, distinguindo um ser de outro no que concerne às suas ações. É a espontaneidade que indistingue o agente de sua ação, não permitindo ações padronizadas. E o juízo reflexivo é aquele juízo que sempre exige reflexão, pensamento, ou seja, não é um juízo pronto, como uma fórmula. Foi o que Hannah Arendt disse que o nazismo não deu conta de responder com o juízo determinante, de Kant.

Eichmann se torna, então, um marco do laborans que não pensa; apenas executa a monotonia de sua atividade irrefletida e inconsequente. Arendt invoca seu nome para muitas constatações, e é possível aqui questionar, em especial, o quanto esse padrão de comportamento, ao invés de ação, sugere a mesma limitação em uma sociedade a qual consumir é o fator preponderante de "cidadania"? Sendo a concepção arendtiana de política voltada ao dissenso entre seres singulares cuja imprevisibilidade da ação é o que encerra a possibilidade do novo, a inexistência de um convívio que permita essa compreensão torna o agente alguém não propriamente responsável pelo seu discurso e sua revelação, mas mero reprodutor de comportamentos fabricados que nada manifestam sobre sua identidade única, e contribuem ao sentido moderno da política cujo mundo de aparências se deformou em um código comportamental que diz mais sobre seres adaptados que sobre seres singulares. Afinal, o direito legitima que cada um possa ser juiz de si mesmo; não há nenhuma necessidade formal de validação das próprias opiniões junto aos demais que vivem no mesmo espaço compartilhado, desde que cumpridas as leis positivistas. Esse evento dificulta o exercício do juízo político e de uma cidadania que não seja apenas periférica.

A acepção moderna da sociedade ocidental compreende a comunidade política como uma fraternidade, reinando o consenso e a opinião anônimos, a unidade muda, a inviabilização de uma esfera pública que torne as relações e conexões entre seres humanos livres e ativos uma possibilidade. Enquanto predominava como objetivo dos antigos a ideia de uma partilha do poder político entre os cidadãos ${ }^{12}$ de um corpo social - o que, para eles, significava liberdade, - entre os modernos impera uma necessidade de segurança dos privilégios privados, localizando a liberdade nas "garantias concedidas pelas instituições a esses privilégios" (CONSTANT, 1985, p. 15). Além disso, o respeito também parece partir mais agora sobre as posses materiais adquiridas que sobre aquilo que uma pessoa cidadã possa dizer ou fazer, tal como um feito digno de notabilidade por sua virtude; e isto situa a querela da propriedade privada acima do interesse pelo bem comum. Uma vez que, para Arendt, o que torna possível o espaço de visibilidade pública (ação + pensamento) é

12 Nesse caso, preservo apenas a forma masculina (cidadãos), pois à época as mulheres não eram consideradas passíveis de exercer cidadania.

SILVA, Kelly Janaína Souza da. Sociedade de Consumidores e o desinteresse pela esfera pública: escravização invisível e a política instrumental em Hannah Arendt. Griot : Revista de Filosofia, Amargosa - BA, v.19, n.2, p.218-229, junho, 2019. 
a pluralidade humana - conditio per quam de toda a vida política - a atualidade se encerra, à vista disso, como um momento de obscurecimento da diferenciação entre as esferas da vida pública e da vida privada, o que transforma as comunidades modernas em sociedades de operários e assalariados, centradas em torno do trabalho (ARENDT, 2010, p. 56), do consumo e dos interesses particulares.

Tal centramento é um dos pontos chave para a conversão de uma sociedade de massa em uma sociedade de consumidores. A glorificação teórica do trabalho cumpre, juntamente com o esfacelamento da tradição, a influência necessária a que a primazia do reino das necessidades prevaleça sobre a dignidade das ações políticas. Na obediência ao processo de busca pela sobrevivência, a omissão de pensamento não questiona o sentido das ações e deixa o ator político em condição apenas instrumental junto ao espaço público, não desenvolvendo juízos reflexivos. $\mathrm{O}$ ciclo vital e sua manutenção se manifestam, aparentemente, como algo mais fundamental à vida humana que a atividade do espírito. $O$ pensamento, a vontade e o julgamento, tanto na esfera pública quanto privada ficam, assim, comprometidos, ante a necessidade de ganhar o próprio sustento e assegurar a produção das coisas (artificiais) indispensáveis à manutenção da vida. Prepondera sobre as massas a criação de necessidades comuns dadas pela cultura ${ }^{13}$ e pela propaganda, de modo a instigar a uma forma de vida pautada em uma única felicidade possível, com valores e interesses ligados ao ciclo de produção capitalista.

Essa proposta de felicidade possível é mais básica e primeira, entretanto, cumpre papel importante quando não há o conhecimento de outras formas de experimentá-la. Como diz Arendt, é uma felicidade vulgarizada no contentamento, que solidifica em um ideal "a realidade fundamental de uma humanidade trabalhadora" (ARENDT, 2010, p. 133). Trata-se de uma felicidade que se traduz à custa da exigência de que o animal laborans, enquanto pertence a uma sociedade da massa, atenda ao equilíbrio entre "os processos vitais de exaustão e regeneração, de dor e de alijamento da dor" (ARENDT, 2001, p. 146). Isto implica que suas horas vagas lhe distraiam ao consumo - a ideia capitalista do que é ser feliz; - e quanto mais tempo livre, então, tiver, maiores serão seus apetites. Esse consumo, aliás, inclui a diversão e o entretenimento, que se tornam insaciáveis e necessitam ser industrializados, além das mais diversas demandas que podem objetificar-se em mercadoria. E é também a partir da exigência de satisfação desses apetites que a questão da durabilidade (ou de sua ausência) se apresenta, pois para que se mantenha a máquina de produzir e consumir, o desperdício e a aniquilação por meio do consumo são essenciais ao ritmo produtivo. É a partir desses fenômenos que o ideal de "sociedade de consumidores" é erigido: na modernidade ocorre uma extensão dos antigos limites da esfera das necessidades, pois agora há um processo artificial para supri-las, além de possibilitar sempre a criação de novas.

Assim, a formação humana das pessoas desse tempo se constitui a partir de princípios voltados à produção, ao consumo, ao lucro e à acumulação, compondo a cidadania como público consumidor, inclusive de cultura ${ }^{14}$; e a esfera pública

\footnotetext{
13 Costuma-se definir cultura, à maneira da sociologia francesa, como o conjunto de obras de elevação do espírito; ou então, ao modo da antropologia norte-americana, como a rede de sentido que perpassa todas as instituições sociais e distingue o humano do natural. No contexto destacado, a palavra cultura serve ao segundo conceito. 14 Aqui, o termo cultura atende ao primeiro conceito.
}

SILVA, Kelly Janaína Souza da. Sociedade de Consumidores e o desinteresse pela esfera pública: escravização invisível e a política instrumental em Hannah Arendt. Griot : Revista de Filosofia, Amargosa - BA, v.19, n.2, p.218-229, junho, 2019. 
moderna como um palco mercadológico. Constituída de uma maneira a não ser percebida como condicionamento, a fundação da cidadania contemporânea equaciona os indivíduos a partir de uma moldura social, e não da possibilidade do agir público, o que incide na limitação de seu ócio ao prazer encontrado fora do trabalho (por meio dos hobbies, entretenimento, indústria cultural e diversão).

A palavra trabalho, a propósito, deriva do latim tripalium, que era um instrumento de tortura utilizado na Idade Média. A partir da era industrial, sua ascensão torna-se um culto ideológico que consolida o advento do capitalismo, reduzindo o corpo biológico a um instrumento adaptado a essa empresa, e naturalizando o trabalho enquanto destinação ontológica humana. Trabalhar tornase, então, como que uma forma contemporânea de "servidão voluntária" 15 que, uma vez que serve ao capital, tem por objetivo buscar sempre mais produtores, além de descobrir potenciais consumidores e excitar-lhes os apetites, criando necessidades artificiais que sempre precisam se reinventar. Dessa forma, tem-se um esvaziamento da política que reduz os cidadãos e as cidadãs puramente a "consumidores políticos", porquanto veem seu individualismo associado à sua liberdade.

Sua capacidade de sair do condicionamento imposto está intrinsecamente ligada ao exercício da faculdade de pensar que, como consequência, deriva a constituição de uma comunidade política verdadeira por meio do sensus communis e do exercício do juízo - seus elementos centrais, - uma vez que não, necessariamente, se encerram sob os comportamentos e regras pré-definidos pela sociedade de massa. Isto quer dizer que, ao invés da ação - seja esta a ação política propriamente dita, ou a simples ação espontânea ou reação inusitada, - espera-se que cada membro da sociedade obedeça a certo tipo de comportamento, pelo qual será considerado "normal", ao mesmo tempo que, de forma menos evidente, terá sua aptidão de pensamento comprometida. É essa uniformização comportamental que converge a uma época indiferente à ação como fator político, contribuindo à instituição da normalização que produz os sujeitos dóceis, apontados por Foucault como resultado do adestramento e da construção de subjetividade ${ }^{16}$, ou ainda, o modelo de sociedade de controle, retratada por Deleuze ${ }^{17}$. A grande ironia é que a liberdade, de certa forma, é o que dá sentido à política, pois na esfera privada permite a união humana em torno do suprimento de necessidades e carências; e no âmbito público move a ação e o discurso para o estabelecimento de acordos entre seres que desfrutam de uma igualdade coletiva, ainda que conservem diferenças singulares (BONFIM, 2011, p. 90). Considerando que a finalidade da política é ela mesma, nesse caso, ela deriva da ação, e não do trabalho ou da fabricação (labor and work).

Nesse sentido, é possível afirmar, a partir das análises arendtianas, que na ilusão de uma liberdade individualista, falta às pessoas que compõe uma massa um sentimento que as faça perceber um interesse comum como algo mais elevado que seus desejos particulares, o que desarticula o sensus communis e leva cada ser à superfluidade, uma vez que inexiste a consciência de que se vive em um mundo

${ }^{15}$ Referência à obra De la servitude volontaire ou le contr'un. Discours, de Étienne de La Boétie.

${ }^{16}$ Sobre isso, ver: FOUCAULT, Michel. Vigiar e punir: história da violência nas prisões. Trad. L. M. P. Vassallo. Petrópolis: Vozes, 1987.

${ }_{17}$ Para saber mais: DELEUZE, Gilles. Post Scriptum sobre as sociedades de controle. In: Conversações. Trad. Peter Pál Pelbart. São Paulo: 34, 1992.

SILVA, Kelly Janaína Souza da. Sociedade de Consumidores e o desinteresse pela esfera pública: escravização invisível e a política instrumental em Hannah Arendt. Griot : Revista de Filosofia, Amargosa - BA, v.19, n.2, p.218-229, junho, 2019. 
conjuntamente habitado cujas ações políticas importam; e tal fato ainda reduz sua própria existência a apenas um número na espécie humana. Pode-se dizer que o que temos atualmente é uma grande massa de consumidores: consumidores de sonhos, de ilusões (vendidos pela propaganda); consumidores de padrões (geralmente reproduzidos e inquestionados); consumidores de imagens; consumidores de relações humanas (muitas vezes, moldadas pelas mídias); consumidores de sexo, de aculturamento; consumidores de emoções, de sensações; consumidores de "política" (ou o que quer que isto seja); consumidores de ideologias (muitas, manipuladas); consumidores de ciência e de discursos ditos científicos. A lista poderia ser mais extensa. E para Arendt, se utilizar da máxima de que "tudo é possível"18 conduziu a raça humana mais à destruição de suas qualidades sensíveis do que ao progresso, contribuindo à dilatação do poderio econômico e tecnológico (ainda que, segundo Marx, esta levaria a humanidade ao encontro da liberdade, porém parece ter apenas colaborado para que a espécie se contentasse em ser o limitado animal laborans moderno).

A partir disso, enfatizo, quando a política passa a ser vista como mera "função da sociedade", ela perde sua razão de ser na liberdade. Ou, ao menos, na liberdade política por excelência, traduzida no fenômeno mundano da ação. E desde o momento em que liberdade e pluralidade não se mostram mais como os elementos fundamentais da esfera política por definição, a sociedade passa a se guiar pela conformidade, e não pelo protagonismo de seus atores políticos, o que conduz, inevitavelmente, a todo o cenário descrito e testemunhado, e ainda, pela ignorância deste. Logo, a extensão da esfera das necessidades na modernidade é inerente ao capitalismo para que se mantenha a humanidade como mera classe animal que nasce, cresce, trabalha, se reproduz, consome e morre. Aqui, importa inquirir acerca do papel da pluralidade e da liberdade em relação ao espaço político, para refletir a crescente despolitização de nosso tempo aliada não só à proeminência do ciclo vital, mas também da alienação que envolve o animal laborans em sua vitória sobre o zoon politikon. Qual a dignidade conferida à singularidade nessa nova configuração política? O quanto singularidade vem sendo confundida com individualismo?

Prover o próprio sustento é uma necessidade elementar, é verdade. Entretanto, a soberania contemporânea do trabalho sobre a vida ativa do espírito pode significar apenas a completa submissão da raça humana à necessidade. Nessa perspectiva, o rompimento da tradição contribuiu substancialmente à negação de que cada indivíduo conheça e participe o mundo que o cerca tendo o pensamento como condição essencial - e essa circunstância impõe que o sensus communis readquira sua importância para as pessoas da massa. Somente assim, a gradual libertação de uma escravização invisível pelo ciclo vital, e o exercício de uma política além de meramente instrumental, poderão ser reconhecidas.

\footnotetext{
18 Procurando, sistematicamente, eliminar a diferença entre cada ser humano singular, os campos de concentração do totalitarismo demonstraram a crença de que tudo é possível na medida em que reduziram esses seres à mera uniformidade de reaçōes. Logo, não se tratava apenas de exterminar seres humanos, mas também de minar, com a precisão do controle científico, a própria espontaneidade, transformando a "personalidade humana numa simples coisa, em algo que nem os animais são" (ARENDT, 2000, p. 488).
}

SILVA, Kelly Janaína Souza da. Sociedade de Consumidores e o desinteresse pela esfera pública: escravização invisível e a política instrumental em Hannah Arendt. Griot : Revista de Filosofia, Amargosa - BA, v.19, n.2, p.218-229, junho, 2019. 


\section{Referências:}

ARENDT, Hannah. Vita activa oder Vom täigen Leben. Stuttgart: Kohlhammer Verlag, 1960.

ARENDT, Hannah. Origens do Totalitarismo. Trad. Roberto Raposo. São Paulo: Companhia das Letras, 2000.

ARENDT, Hannah. A condição humana. 10 ed. Tradução R. Raposo. Rio de Janeiro: Forense Universitária, 2001.

ARENDT, Hannah. A vida do Espírito. O Pensar, o Querer, o Julgar. Tradução de Antônio Abranches. Rio de Janeiro: Relume Dumará, 2002.

ARENDT, Hannah. Trabalho, obra, ação. Tradução Adriano Correia. Cadernos de Ética e Filosofia Política, São Paulo, n. 7, v. 2, p. 175-201, 2005.

ARENDT, Hannah. A condição humana. Tradução R. Raposo, revisão técnica: Adriano Correia. Rio de Janeiro: Forense Universitária, 2010.

BONFIM, C. A despolitização moderna à luz do pensamento de Hannah Arendt. Cognitio Estudos: São Paulo, v. 8, n. 2, p. 86-95, 2011.

CONSTANT, Benjamin. Da liberdade dos antigos comparada à dos modernos. Trad. L. Silveira. Revista de Filosofia Política, n. 2, p. 15, inverno/1985.

CRARY, Jonathan. 24/7 - Capitalismo tardio e os fins do sono. Tradução: Joaquim Toledo Jr. São Paulo: Cosac Naify, 2014.

DELEUZE, Gilles. Conversações. Trad. Peter Pál Pelbart. São Paulo: 34, 1992.

DUARTE, André. Hannah Arendt e a modernidade: esquecimento e redescoberta da política. In: CORREIA, Adriano (org). Transpondo o abismo: Hannah Arendt entre a filosofia e a política. Rio de Janeiro: Forense Universitária, 2002.

FOUCAULT, Michel. Vigiar e punir: história da violência nas prisões. Trad. L. M. P. Vassallo. Petrópolis:Vozes, 1987.

TOCQUEVILLE. A democracia na América. Trad. João Miguel Pinto de Albuquerque. São Paulo: Nacional, 1969.

Autor(a) para correspondência: Kelly Janaína Souza da Silva, Universidade Federal de Santa Catarina, Campus Reitor João David Ferreira Lima - Bairro Trindade, 88040-900, Florianopolis SC, Brasil. kelly_phoenix@hotmail.com

SILVA, Kelly Janaína Souza da. Sociedade de Consumidores e o desinteresse pela esfera pública: escravização invisível e a política instrumental em Hannah Arendt. Griot : Revista de Filosofia, Amargosa - BA, v.19, n.2, p.218-229, junho, 2019. 